\title{
Meaning in Life and its Vitality in the Praxis
}

\author{
Jobi Thomas Thurackal ${ }^{*}$
}

\begin{abstract}
This paper examines the different aspects of meaning in life from a theoretical perspective of philosophy and psychology. It deals mainly with the dynamism of meaning in life on the basis of contextual perspectives and its emergence from different sources. In this regard, religion plays an important role in the formation of meaning in life, especially in relation to its competence. Moreover, the praxis of meaning in life is processoriented and is different from the purpose of life. It also remains as a connector between the existential vacuum and the reality of life, promoting stability in life. The expression of meaning in life can be based on both low and high levels. Above all, meaning in life can be seen from two different aspects of presence of meaning and search for meaning, specifically from the empirical and Indian contexts.
\end{abstract}

Keywords: Meaning in Life, Sources of Meaning in Life, Presence of Meaning, Search for Meaning, Religions

\section{Introduction}

"We worry about the meaning of life when we have lost our zest for living ...." says Raymond A. Belliotti (2001, p. 9) in What is the meaning of human life? He describes that human life can be positively engaged only when one enjoys a complete sense of meaning in life. In this sense, he brings out two types of engagement in the process of making meaning in one's life. The

* Dharmaram Vidya Kshetram, Bengaluru, India; jothura@gmail.com 
first type of engagement is "to be so filled with a sense of meaning, purpose, and value, to be so much in tune with the rhythms of the universe, that our exuberance and visceral certainty that our lives make sense renders philosophical reflection on these matters unnecessary" (Belliotti, 2001, pp. 9-10). The second type is "to be so immersed in daily habits, routines, and distractions that we fail to reflect. We make our lives more animal-like by throwing ourselves into patterns that we experience as necessary and self-evident. Our failure to reflect on what we are doing is not the product of our overabundant sense of life, but the result of a weakness of the will, a relinquishment of freedom, a life of bad faith." (Belliotti, 2001, p. 10). The first approach is a natural tendency of the human beings to find meaning in life, engaging in the natural capacities, whereas the second approach is mostly depended upon one's cognitive capacity to reflect upon the events to generate meaning in life. In this sense, the meaning of life can be reflected distinctively in response to the question of the purpose or value of human life. Interestingly, at this juncture, Belliotti distinguishes both meaning and purpose, where the former implies how a person "understand[s] or make[s] sense of life in an ongoing way", and the latter implies "the goals or ends, or the highest or final end, toward which [one] strive[s]" (Belliotti, 2001 , p. 10). Hence, meaning can be understood as processoriented, whereas purpose as goal-oriented, and both act simultaneously in the process of making sense of one's life.

\section{Dynamism of meaning in life}

In this regard, William Gerber (1994) describes dynamism of meaning in life from different life situations of the people. For some people, they can find a definite meaning in their lives because of the development of a positive net balance in their lives. They achieve their goals, or at least experience reasonable progress in the attainment of their goals, where the positives dominate the negatives. For some others, even though the external positives may not overweigh the negatives, they interpret the life events as a part of God's plan. This approach enables them to find meaning in their lives eventually. As a consequence, the positives will dominate the negatives ultimately. For the existentialists, says Gerber, life is absurd, but one can transcend the absurdity or stand above it and thereby he or she can generate meaning in life. 
However, Betty (1984) brings another criterion to generate meaning in one's life. In his opinion, most people place themselves in the context of eternity in order to have meaning of life. Moreover, they consider the present as meaningful only when it points to the future. Viktor Frankl rightly puts it, "It is a peculiarity of man that he can only live by looking to the future" (Frankl, 1962, p. 72). In other words, most people perceive the future life as more meaningful than the present life. Hence, Betty (1984) explains, "Life becomes ultimately meaningful when there is the belief or trust that there is somewhere in one's future a goal of surpassing, even infinite good to be realised and that what we do in the present is significantly related to this goal." (pp. 31-32)

Considering the above mentioned concepts, the consolidating ideas of meaning in life by Hartshorne (1996) is more acceptable in the contemporary world. For him, people can execute their plans made in the past in the present and continue to bring out new plans for the future. Hence, he argues that every moment in life is meaningful because of the fulfillment of the past and preparation for the future. In this sense, "the meaning of life is life itself" (Hartshorne, 1996, p. 11). Each person has meaning or purpose in life for the sake of the life of others. In this way, meaning in life depends on what the present does for the future and what a human being does for his or her fellow being (Hartshorne, 1996). This leads to the question of the generating principles of meaning in one's life.

\section{Sources of meaning in life}

Agera (1986) brings out the different sources of meaning of life, stating that "[e]ach area, or compartment, of life can serve as a fountainhead of meaning in life" (p. 381). To gather and relate the meanings from different sources of life is an important sociopsychological task. He argues that any failure in the process of gathering meaning from various compartments of life can cause mild to severe damage to one's life. Furthermore, the experience of meaning is "an experience of a totality in which all the particular meanings have coalesced" (p. 382) and not merely 'an experience of the diversity in unity'. This emergent totality is innovative and integrated intensively to one's life experience. Hence, Agera calls this amalgamated and integrated whole as a Gestalt (configuration). 
He illuminates further the significance of gestalt in the process of meaning making:

The Gestalt cannot be derived from any one particular compartment of life, because it possesses within itself the total significance of life. Indeed, it is the Gestalt that gives meaning to the particulars. The Gestalt is the end (teleios) and the goal (telos) of the dull particulars. This is the reason why I maintain that the isolated meanings, flowing from a compartmentalized life, cannot satisfy the demand for the fullness of meaning that lies at the core of one's being. (p. 382)

Hence, Agera reasons that reality is the ultimate context of all meaning', where a person derives meaning in life from his or her experience of reality. As a result, meaning in life has not merely cognitive aspect alone, but it has affective, conative and biological realms too. Thus, he describes life as "an apprehension of realities in an attempt to coherently and significantly relate them to oneself" (p. 385). In this sense, meaning of life can be viewed as the totality of human experience. Furthermore, meaning in life depends on the manner of a person's being, which is integrated with the world through the physical, psychological, social, and even transcendental realms of life. In line with Betty (1984), Agera finds the total meaning of life in a 'final future of human beings' that he calls 'the horizon' of human beings. From this understanding, religion supports a person to find 'an immediate awareness' of this horizon in human beings, which can be called as Moksa, Brahman, Nirvana,..., God, Beatific Vision, Eternal Happiness, Immortality and so on. This awareness of the horizon leads to the final destination of a person, and according to Agera, it is "the meaning of all our anticipated totality of life" (p. 389). His perspectives on meaning in life gives a new phase of thought from the context of religious concepts and the role of religions in the making of meaning in one's life.

\section{Significance and role of religions in meaning in life}

Religions can contribute largely to the meaning of life. As Ward (2007) perceives, they are "belief-systems which articulate, with different degrees of systematization, competing theories about the 
meaning of human life" (p. 11). They may deal with the daily issues of the people that can devalue the purpose of one's life that include sufferings, depression, or anxiety, affecting the meaning in life seriously. In this context, religions can empower the followers to reflect on the best way to cope with the life problems and to face life with full of hope and to lead a worthwhile life. In this way, positively functioning religions support its followers to lead a life with integration and fulfillment. Such people are encouraged to foster both social and personal values and promote worthwhile patterns of life together. Ward (2007) describes the qualities of those people: "They encourage a search for what gives self-worth and lasting satisfaction. They encourage positive thinking about life's prospects. They often provide group affirmations to establish such positive patterns more effectively. They aim at strong, affirmative, creative attitudes, and the overcoming of negative and self-destructive tendencies. They offer forms of training which may overcome destructive impulses and lead to greater wisdom, equanimity, and happiness" (pp. 18-19).

Furthermore, religions apply different strategies to achieve meaning in life. In Christianity, for example, prayer is the expression of reverence, gratitude, self-examination, and compassionate love that helps a person to lead a meaningful life in a community of love. In Hinduism, devotion, meditation, and ritual activity can help the follower to awaken the mind to the consciousness of the Supreme Self and thereby to find meaning in life. Moreover, in Buddhism, meditation is the key method to lead a meaningful life, where the follower overcomes the sense of self and of attachment to finite goods and enjoys tranquility and joy by overcoming greed, hatred, and delusion (Ward, 2007, p. 19). Meanwhile, in Islam, the meaning in life is understood in the context of "submission to the will of God and serving as his deputy on earth", who consecrates his life and deeds to proclaim the divine revelation (Paterson, 2009, p. 145).

Religions perceive human beings as the sufferers of illusion, ignorance, or depravity, blinding the highest value. In this context, religions aim at positive complete meaning to human life, helping the people to achieve the highest value. For instance, Christianity believes that God creates human beings for a purpose, which is 
intended to achieve "the potentialities for understanding, creativity, and community that have been implanted by the creator" (Ward, 2007, p. 20).

Human life is meaningful, when a person can associate life events with an intelligible pattern that can emerge in relation to the past events of life. Life becomes meaningless, when the association does not take place positively. Such people cannot find the means to fit the events into a general pattern. Based on this phenomenon, Ward (2007) describes the meaning of life as the capacity of a person "to see how its various elements fit into a unique, complex, and integrated pattern" (p. 22). In this process, religious people may place the supreme value as the final purpose of life that includes a state of wisdom, compassion, and bliss that creates meaning in their lives. In order to attain it, religions use different strategies, including rigorous forms of renunciation, meditation, strictly disciplined life based on scriptural values, and so forth.

In this line of thought, Quinn (2007) argues about the positive intrinsic value of human life because of its inviolability. If the intrinsic value of the whole humanity can be seen as its totality from individual life of every person, then the former can be positive as well as meaningful for every human life. This positive intrinsic value is enough to create meaning in one's life. Hence, Quinn proposes three types of meaning where the first type of the positive 'axiological meaning' (AM) that can be found in human life when it possesses positive intrinsic value for the wellbeing of the person. The second type is the positive 'teleological meaning' (TM) in human life that can possess purposes with positive value that are nontrivial and achievable through actions. The third type is the positive 'complete meaning' in human life that can be attained through the presence of both the positive axiological and teleological meanings.

Hence, meaning can be one, but its fountainhead can be different. Nevertheless, bringing the meanings together from different areas or compartments of life is a difficult task. Agera (1986) discusses the concern in the following way: "The unification of meanings drawn from various compartments of life is a serious sociopsychological task. Serious because the task, while being psychological acumen on the part of the individual to retain the 
diversity of various aspects of life and at the same time relate them all as emanating from a single unified life" (p. 381). Similarly, if the unification of meanings fails, the human life can be affected detrimentally.

\section{Competence of meaning of life}

Naturally, then arises a question: what is the experience of meaning? Agera views it as the total experience of all the particular meanings that are being collected and not merely an experience of the diversity in unity. Moreover, the emergent totality is anew and fully integrated in the experience of human life, which he calls a "Gestalt", a configuration. In this sense, reality is the eventual framework of every meaning and therefore, meaning in life can be achieved through the experience of reality. Agera reasons further that, "Life is then an apprehension of realities in an attempt to coherently and significantly relate them to oneself. Hence the meaning of life should refer ultimately to the totality of human experience...." (p. 385). It is essential because of its incarnated and concorporated approach to the world along with the manner of the being of humans. Furthermore, the 'how' of the meaning implies the 'what' of it. In this way, the final meaning in life can be found in the ultimate goal of human beings and the major religions of the world give different expressions like eternal happiness, salvation, liberation, immortality and so on (Agera, 1986). Betty (1984) also expresses the same line of thought that human beings commonly perceive their lives as meaningful only when they encounter it in the context of eternity.

Moreover, to achieve the final goal from the religious perspective, each individual strives to fulfill the meaning of each moment by carrying out the goals of the past and making the new ones for the future in the present. Hence, as Hartshorne (1996) rightly describes, "meaning of life is life itself" (p. 11), which is intended not only for oneself but for the life of others. In this way, the present is meaningful only when it directs to the future which is more promising than the present. Moreover, the ultimate meaning of life can be found in people who seek their future goal to reach the infinite good (Betty, 1984). 
In the same line of thought, William Gerber (1994) describes meaning in life from different life situations of the people. For some people, they can find a definite meaning in their lives because of the development of a positive net balance in their lives. They achieve their goals, or at least experience reasonable progress in the attainment of their goals, where the positives dominate the negatives. For some others, even though the external positives may not overweigh the negatives obviously, they interpret the life events as a part of God's plan. This approach enables them to find meaning in their lives eventually. As a consequence, the positives will dominate the negatives ultimately. For the existentialists, says Gerber, life is absurd, but one can transcend the absurdity or stand above it and thereby he or she can generate meaning in life. ( $p$. 162). This competency of meaning in life understood by every human being enables us to put it into practice.

\section{Praxis of meaning in life}

However, Belliotti (2001) looks into the praxis of meaning in life. For him, the worry about the meaning of life activates when one has lost the passion to life or if he or she has too much time to spare with. At this juncture, persons may engage in life either in tune with the rhythms of the universe or by immersing in daily habits, routines, and distractions that one fails to reflect. Belliotti further states, "[w]e make our lives more animal-like by throwing ourselves into patterns that we experience as necessary and selfevident. Our failure to reflect on what we are doing is not the product of our overabundant sense of life, but the result of a weakness of the will, a relinquishment of freedom, a life of bad faith" (p. 10). In this sense, the meaning of life can be assumed better in relation to the purpose or value of human life or in the totality of life itself. Belliotti thus, differentiates both meaning and purpose of life. For him, the meaning is process-oriented, where people "understand or make sense of [their] lives in an ongoing way" (p. 10). On the other hand, purpose is goal-oriented, where people search for the ends of their lives. In this way, purpose can be considered to be "a subjective sense of one's life as meaningful" (Bronk, 2014, p. 4). Besides that Bronk proposes the factors of commitment, goal-directedness, and personal meaningfulness as the three aspects of purpose in life that are necessary as well as 
sufficient to discern the presence of purpose (Bronk, 2014). Furthermore, a life purpose gives meaning not only to one's personal life but also helps the person to engage in the world beyond one's self. It is more over evident when a person commits himself/herself for a social cause. Recent studies prove that those individuals who act beyond their selves are having integrated personality dispositions, higher levels of achievements and openness, psychological adjustment, more satisfaction in life (Bronk, 2014). Meaning and purpose, though distinctive in nature, are closely related. The quest for meaning directs a person to find his or her place in the surroundings and shapes a sense of self and purpose (Bronk, 2014; Parks, 2011). In other words, the existential meaning often influences the nature of the purpose of life (Bronk, 2014).

In this perspective, Viktor Frankl $(1965,1992)$ discusses the concept of existential vacuum where a person perceives no meaning or purpose in life. To overcome this vacuum, Frankl brings out the need to actualise values in life and proposes three types of values to be practiced in life. The values need to be creative, experiential, and attitudinal. When a person is creative, he or she contributes something to the outside world, for example, writing an academic paper. The experiential values include anything that is experiential, such as sensing, hearing, seeing, and so forth. Meanwhile, the attitudinal value is the mind-set of a person to save oneself from sufferings. In this way, meaning in life remains as a connector between the existential vacuum and the reality of life, where it serves as "an imposition of a stable conception onto a changing biological process" (Baumeister \& Vohs, 2002, p. 609). Hence, meaning in life can be considered as a tool to promote stability in human life.

\section{Levels of meaning in life in the praxis}

Furthermore, meaning in life can have both low and high levels. The low levels of meaning include "concrete, immediate, and specific meanings" whereas the high levels of meaning consist of "long time spans and broad concepts" (Baumeister \& Vohs, 2002, p. 610).When a person progresses into the higher levels of meanings, he or she can develop a sense of positive satisfaction and 
fulfillment in life (Baumeister \& Vohs, 2002). In this progress, Baumeister (1991) mentions four significant needs that promote meaning in life. They include the need for purpose, the need for values, the need for a sense of efficacy, and the need for a basis for self-worth. People who achieve satisfaction in all these needs, can lead a very meaningful life. People who are insufficient in one or more of the four needs find difficult to find meaning. Apart from that, meaning in life is drawn from multiple sources, including religion, work, family, positive feelings, community life, and personal projects or missions (Emmons, 1997). These sources can help the people to withstand any of the meaningless situations in life. Also, they can lessen the pressure level to satisfy the four needs of meaning in life (Bumeister \& Vohs, 2002).

\section{Impediments of value gap and existential neurosis}

Similar to the existential vacuum, people may experience the value gap in life, which can be compensated by the promotion of self and identity (Baumeister \& Vohs, 2002). The modern world often fails to provide set of values that can be reliable and satisfactory. Thus the value gap becomes a stumbling block in finding meaning in life (Baumeister \& Vohs, 2002). Parenthetically, the contemporary world has raised "the self to the status of serving as a basic value" (Bumeister \& Vohs, 2002, p. 612). In the modern world, it seems to be a moral obligation of everyone to seek for self-knowledge and to develop and enrich one's talents and thereby aiming at one's personal growth and meaning in life. A paradigm shift from the traditional moral system is obviously evident due to the remarkable change of "the cultivation of self from the enemy of moral values to one of the staunchest bases of moral values" (Baumeister \& Vohs, 2002, p. 612).

In this context, Maddi (1967) suggested the concept of "existential neurosis" that describes "the belief that one's life is meaningless, by the affective tone of apathy and boredom, and by the absence of selectivity in actions" (p. 313). It has the components of cognition, affection, and behaviour. Moreover, it alienates the person from one's self and society (Zika \& Chamberlain, 1992). Supporting the concept of Maddi, Yalom (1980) described that meaninglessness in life is due to psychopathology, whereas positive life meaning is due 
to strong religious beliefs, self-transcendent values, membership in groups, dedication to a cause, and clear life-goals.

\section{Presence of meaning and search for meaning}

Meaning in life, therefore, can be understood from two different aspects. The first aspect of meaning in life is to understand how and to what extent people perceive their lives as significant and meaningful. This dimension can be called the presence of meaning in life and can be defined as "the degree to which people experience their lives as comprehensible and significant, and feel a sense of purpose or mission in their lives that transcends the mundane concerns of daily life" (Steger, Kawabata, Shimai, \& Otake, 2008, p. 661). The second aspect of meaning in life can be described as the search for meaning in life. It refers "to the dynamic, active effort people expend trying to establish and/or augment their comprehension of the meaning, significance, and purpose of their lives (Steger, Kawabata, Shimai, \& Otake, 2008, p. 661). Presence of meaning can be understood as a valued outcome, whereas search for meaning can be seen as a significant process. The former deals with the state of one's life being meaningful and the latter deals with how to make one's life more meaningful. Theoretically, both these components relate to each other and some theorists argue that search for meaning is a basic human motivation that can be simultaneously led to the increase in presence of meaning (Frankl, 1963; Maddi, 1970). However, they are only moderately related to each other and keep a distinctive character statistically (Steger, Kawabata, Shimai, \& Otake, 2008; Thurackal, Dezutter, \& Corveleyn, 2016).

Culture can contribute substantially to enrich the meaning in our lives, since it helps to shape the enriching and meaningful experiences in the people (Kitayama \& Markus, 2000). Researchers found that the relation between presence of meaning and search for meaning are not the same for both western and eastern cultures. The relationship is statistically negative in the Western cultures, whereas it is positive in the Eastern cultures (Dezutter, et al., 2014; Thurackal, Dezutter, \& Corveleyn, 2016). In this perspective, in India, search for meaning is equally important as presence of meaning. Therefore, Indians understand meaning in life in terms of the four important objectives of human endeavour, the 
purusharthas, where purusha is the self and artha is the meaning in life. Four goals of human life, namely, wealth (artha), pleasure (kama), virtue (dharma), and liberation (moksha), define the meaning of the life of every individual. The first goal of life is the artha or wealth, which refers to is the material possessions or the worldly achievements that requires one to satisfy the necessities of life. However, if this becomes the predominant objective of one's life, the higher goals of virtue and liberation could not be achieved and the self would remain in gratifying of the senses and would ignore the spiritual self. Meanwhile, the second goal of life, kama or pleasure, is derived from physical intimacy, cultural pursuits, creativity, and other activities by which one enjoys life. The third goal, dharma or virtue, stands for righteousness that designates a person to do the duty towards one's family, society, and humanity at large, by doing the right things and respecting the societal laws. Finally, the last goal of life, moksha or salvation, is the liberation of the soul from the earthly bondage and union with the divine. The first three objectives contribute to the realisation of the final goal of liberation in one's life (Kautilya, 1992; Sharma, 2004). These four Indian aspects of meaning in life can also be understood universally as the materialistic, hedonic, eudaimonic, and spiritual meaning in life respectively (Thurackal, Dezutter, \& Corveleyn, 2016).

Moreover, the ancient Indian literature suggest that meaning in life or purusharathas can be achieved through the four age-based stages of human life, known as ashramas (stages), namely brahmacharya (celibate studenthood), grihastha (the householder stage), vanaprastha (partial renunciation), and sannyasa (complete renunciation) (Singh, 2008, p. 23). The word, ashrama, is derived from the Sankrit root of srama, which means 'making an effort'. Hence, it is a step-by-step journey of one's life (ashrama) to liberation (moksha), the final goal of human life (Sharma, 2004). Furthermore, each ashrama prepares a person for the succeeding human stage in a systematic way and thereby helps to lead a better life (Sharma, 2004). Hence, each ashrama has objectives that lead to achieve meaning in one's life (Flood, 2005; Herman, 1976; Olivelle, 2003). In this way, search for meaning is an essential aspect in the life of an Indian in order to achieve the perfect meaning in life, the liberation or moksha. 


\section{Conclusion}

Meaning in life has received sustained philosophical and psychological attention, exploring the dynamism of human life with its ultimate objectives. This article is a modest attempt to explore the vitality of meaning in life from an inter-disciplinary viewpoint. Human life has the meaning and it differs from individual to individual due to the availability of resources and the capacity of an individual to attain its potential levels. For the Indians, the two dimensions of meaning in life can be central due the aspects of searching for meaning in order to be perfect in the presence of meaning due to the spiritual facet of human life. The praxis of meaning in life can enhance the vitality of human life, enabling them to be more competent, coherent, and dynamic.

\section{References}

Agera, C. R. (1986). Vital hermeneutics: The problem of meaning in life and its relation to religion. Journal of Dharma, XI(4), 379-396.

Baumeister, R. F., \& Vohs, K. D. (2002). The pursuit of meaningfulness in life. In C. R. Snyder \& S. J. Lopez (Eds.), Handbook of positive psychology (pp. 608-618). Oxford, New York: Oxford University Press.

Belliotti, R. A. (2001). What is the meaning of human life? Amsterdam Atlanta, GA: Rodopi.

Betty, L. S. (1984). Psychical research and the question of ultimate reality and meaning. Ultimate Reality and Meaning, 7(1), 21-33.

Bronk, K. C. (2014). Purpose in life: A critical component of optimal youth development. Dordrecht, Heidelberg, London, New York: Springer.

Dezutter, J., Waterman, A. S., Schwartz, S. J., Luyckx, K., Beyers, W., Meca, A., ... Caraway, S. J. (2014). Meaning in life in emerging adulthood: A person-oriented approach. Journal of Personality, 82, 57-68. http://doi.org/10.1111/jopy.12033

Flood, G. (2005). An introduction to Hinduism. Cambridge, UK: Cambridge University Press.

Frankl, V. (1965). The doctor and the soul: From psychotherapy to logotherapy. New York: Knopf.

Frankl, V. (1966). What is meant by meaning? Journal of Existentialism, 7, 21-28. 
Frankl, V. (1992). Man's search for meaning: An introduction to logotherapy. Boston: Beacon.

Gerber, W. (1994). The meaning of life: Insights of the world's great thinkers. Amsterdam - Atlanta, GA: Rodopi.

Hartshorne, C. (1996). The meaning of life. Process Studies, 25, 10-18.

Herman, A. L. (1976). An introduction to Indian thought. New Jersey: Prentice-Hall, Inc.

Kautilya. (1992). The Arthashastra. (L. N. Rangarajan, Ed.). Delhi, India: Penguin Books.

Maddi, S. R. (1967). The existential neurosis. Journal of Abnormal Psychology, 72, 311-325.

Olivelle, P. (2003). The renouncer tradition. In G. Flood (Ed.), The Blackwell companion to Hinduism. Oxford, UK: Blackwell Publishing.

Parks, S. D. (2011). Big questions, worthy dreams: Mentoring emerging adults in their search for meaning, purpose, and faith. San Francisco: Jossey Bass.

Paterson, A. C. (2009). Three monotheistic faiths - Judaism, Christianity, Islam: An analysis and brief history. Bloomington, IN: AuthorHouse.

Quinn, P. L. (2007). How Christianity secures life's meanings. In J. Runzo \& N. M. Martin (Eds.), The meaning of life in the world religions (pp. 5368). Oxford: One World.

Sharma, R. K. (2004). Indian society: Institutions and change. New Delhi: Atlantic Publishers \& Distributors.

Singh, U. (2008). A history of ancient and early medieval India: From the stone age to the 12th century. Delhi, Chennai, Chandigarh: Pearson Longman.

Steger, M. F., Kawabata, Y., Shimai, S., \& Otake, K. (2008). The meaningful life in Japan and the United States: Levels and correlates of meaning in life. Journal of Research in Personality, 42(3), 660-678. http:/ / doi.org/10.1016/j.jrp.2007.09.003

Thurackal, J. T. (2016). Exploring the role of personality in psychological maturity and spiritual development among Indian emerging adults. (Unpublished doctoral dissertation). KU Leuven, Leuven, Belgium.

Ward, K. (2007). Religion and the question of meaning. In J. Runzo \& N. M. Martin (Eds.), The meaning of life in the world religions (pp. 11-30). Oxford: One World.

Yalom, I. D. (1980). Existential psychotherapy. USA: Basic Books.

Zika, S., \& Chamberlain, K. (1992). On the relation between meaning in life and psychological well-being. British Journal of Psychology, 83, 133145. 